\title{
Using qualitative methodology to better understand why females experience barriers to regular participation in adventure sport in Scotland
}

Morton, Sarah

2017

This is the accepted manuscript of an article published by Taylor \& Francis in the Sport in Society 15 February 2017 available online:

https://dx.doi.org/10.1080/17430437.2017.1284808 


\section{Using qualitative methodology to better understand why females experience barriers to regular participation in adventure sport in Scotland.}

Sarah Morton, University of Abertay Dundee, School of Arts, Media and Computer Games, Dundee, Scotland

Correspondence should be addressed to Sarah Morton; sarah.morton@uhi.ac.uk

\section{Acknowledgements}

Thanks are extended to all those who participated in the study and facilitated activities in relation to the ethnographic and auto-ethnographic phases of data collection. Thank you also to those who made effort to suggest and/or provide connections to others who they considered to have an interest in the study.

\section{Sources of Funding}

The research was funded by Design in Action (DiA) - an Arts and Humanities Research Council (AHRC) Knowledge Exchange Research Hub led by the Duncan Jordanstone College of Art and Design at the University of Dundee, and partnered with; the University of Abertay Dundee, The Glasgow School of Art, Gray's College of Art at the Robert Gordon University Aberdeen, the Edinburgh College of Art and Design at the University of Edinburgh, and the University of St. Andrew's.

\section{Declaration of Conflict of Interest}

No conflict of interest is known or aware of. 
Abstract

The emergence of the 'experience economy' signalled a shift in consumer purchasing patterns - experiences became favoured over possessions. As a result, the adventure sport industry in Scotland has enjoyed significant economic growth. Individual motivations for participating in adventure sport activities vary greatly. Visit Scotland found participants take part; for fun, because they enjoy the scenery, they like a challenge and to socialise. The survey also found that the majority of participants were male. True, female participant numbers have increased also, and females do express an interest in becoming regular participants, however, there is little to indicate a narrowing of inequality.

On the surface, efforts to address this issue are limited. With the exception of the introduction of female-specific clothing - referred to as the 'shrink it and pink it' trend (c. 2010), solutions offered toward solving the problem have been sparse. The established debate about strength, risk perception, and family choices for females is ongoing. However, studies specifically focusing on the deeper, lived experiences of female participants are, at best, in the emergent phases and little has been documented on how these unexplored factors might contribute to the debate.

Taking a qualitative approach this study looked to explore what motivates a female to want to participate in adventure sport activities, what, if any, barriers they make experience, and to offer suggestions that could address any issues identified by the study. To do this an auto-ethnographic methodology was implemented using the researchers own experiences of participating with male and female participants. In-depth interviews were also conducted with female adventure sport participants.

The study found five key themes which may contribute to reasons why females face barriers when attempting to access adventure sport activities, and as such remain underrepresented. Firstly, costs associated with participating; secondly; lack of reliable information; thirdly, having the support of others; fourth, was the general perception that adventure sport is largely unachievable; and, finally; the importance of being part of the adventure sport community. Overlap between themes was also observed and noted.

Keywords: auto-ethnography, adventure sport, Scotland, female underrepresentation, qualitative methodologies 


\section{Introduction}

$\mathrm{S}$

ince the emergence of the experience economy more than a decade ago, the adventure sport industry in Scotland has experienced marked growth in respect of participant numbers. There is little to indicate that this positive trend will not continue, and it is clear that more and more people are choosing to spend time participating in adventure sport activities, such as rock climbing, mountain biking and off-piste skiing.

Much work has been conducted that gives us a better understanding of motivations, and predictions have been offered in respect of future trends. Many of these studies specifically explore methods for sustaining interest and participant numbers, as well as looking at how to encourage more people to try out adventure sport activities. Statistics about participant demographics are also widely published, and from this we have been able to establish that although both male and participant figures have increased there remains a notable difference between the number of males who participate on a regular basis, and the number of females who do so. Little work has been done to establish why this remains the case, beyond the obvious ability (strength) and family commitment debates.

This study looked to gather data on the lived experiences of female adventure sport participants to explore this gap in knowledge, and develop a better understanding of what factors can motivate a female to take part in an adventure sport activity; to establish what, if any barriers they may experience while doing so; and to consider what steps may be appropriate in beginning to address any barriers identified by the study.

Pine and Gilmore (1999) suggested that the emergence of an experience economy would signal a replacement of agrarian, industrial and service-focused economies with an increased desire for more meaningful economic offerings. They believed experiences would be the foundations for future economic growth, a previously untapped market for potential, and suggested it sensible for businesses, retailers in particular, to take note and adapt marketing tactics appropriately. Schmitt (1999, p. 3) followed this up, stating;

'We are in the middle of a revolution. A revolution that will render the principles and models of traditional marketing obsolete. A revolution that will change the face of marketing forever. A revolution that will replace traditional feature-and-benefit marketing with experiential marketing.'

Kelly and Littman (2008) bring this theory of the 'experience economy' to life, describing it as one where "consumers wear experiences as badges of honor". Indicating that there is greater value in what one can achieve, as opposed to what one can possess.

Of course, what exactly can be defined as an 'experience' could be argued as being matter of opinion. The Cambridge Advanced Learner's Dictionary defines an experience as; 'something that happens to you that affects the way you feel'. Poulsson and Kale (2004, p.271) discuss the links between the experience economy and commercial experiences, they believe;

'...for an encounter to be labeled as an experience, one or more of the following sensations and feelings need to be apprehended by the customer: personal relevance, novelty, surprise, learning and engagement'. 
They follow on to offer the notion that; 'the greater the assortment of these sensations, the more will be the intensity of the experience'. These sensations and feelings suggested by Poulsson and Kale can be tied in with those reported by novice adventure sport participants who may initially be motivated to participate for excitement and thrill (Celsi et. Al., 1993). However, it must be noted that this motivation changes with experience (Celsi et., al., 1993) and there is little to suggest a relationship between sensation seeking and experienced adventure sport participants (Slanger \& Rudestam, 1997; Breivik, 1996; Brymer, 2010).

Although there is little evidence or literature that specifically explores the topic, it is likely that the emergence of the 'experience economy' has assisted in the growth of the adventure sport industry in Scotland. The British Mountaineering Council (2003) report a steady increase in participant numbers, however, they document problems reaching an exact figure to represent exact growth. According to the most recently available Mintel Intelligence report of relevance to the study: 'Sporting Activities in the Great Outdoors' (January 2002), it is estimated that $25 \%$ of the UK population participate in adventure sport activities on a regular basis (once per month or more) - an increase of more than $40 \%$ since 1989.

The British Mountaineering Council (BMC) discusses a set of anecdotal observations that support the visible increase in popularity of adventure sport activities:

- Increased number of retail outlets

- Pressure for parking spaces at adventure sport venues

- BMC membership figures - year-on-year increases

- Increased media coverage

- Increased fashion interest in outdoor clothing

Statistics representing gender participant figures are sketchy, however, the BMC (2003) estimate that of their members $84 \%$ of $19-30$ year olds are male, and $89 \%$ of $31-45$ year olds are male. For the females, 19-30 year olds make up 16\% and 31-45 year olds just $11 \%$. The survey found the most popular adventure sport activities to be: summer mountain walking, winter mountain walking and rock climbing. Visit Scotland (2006) report keen interest in mountain walking, mountain biking and paddle sports.

Although exact figures for UK adventure sport participation show scope for more focused research, it is clear from statistics that do already exist, there has been a definite increase in interest. Brymer (2010, p.218) states that; 'over the past two decades, participation rates in extreme sports have grown exponentially far outstripping the growth rates of any other sport activity' (American Sports Data, 2002; Pain \& Pain, 2005). Puchan (2004) also believes this trend to be more than 'just a flash in a pan, but a sign of the times' (Puchan, 2004, p.177).

It is, therefore, no surprise that Scotland, offering some of the most attainable and accessible world-class adventure sport facilities (SportScotland, 2012) has enjoyed benefit from this increase in participant numbers. However, it is unclear why female participant figures remain lower in comparison to male participant figures, even though females express enthusiasm toward becoming established members of the adventure sport community. Brevik (2010) suggests the number of female adventure sport participants will continue to rise; however, he describes these females as 'trendsetters', perhaps a silent acknowledgment to the clear gender under-representation. Brevik goes on to state that he believes; "it is likely that women will catch up with men in many adventure sports in the future in both number and 
performance". Further elaboration on this thought is not given, and as such, shows scope for further research.

Brevik (2010) describes the adventure sport industry to be adaptable, innovative and accustomed to embracing change. The industry makes use of design and cutting edge technologies to manufacture equipment and clothing; has demonstrated an ability to utilize online promotional resources and social media channels to communicate what it has to offer, and has become a mainstream option once only obtainable by those with the cash funds, ability and insider information required to become an adventure sport participant.

Taking into consideration the following three factors - the 'experience economy', female desire to become established adventure sport participants, and what is perceived to be an open community - it is unclear why male participant figures continue to exceed that of female participant figures. Suggestions as to why this is the case are beginning to emerge, however, solutions are sparse and potentially complex and time-consuming to implement. The desire for an immediate answer is strong, and within such a fast-paced industry the implementation of suggested solutions may not be bold enough to be allocated the time required in order for them to take root.

\section{Experiences and Adventure Sport}

During the past two decades much has been documented about the emergence and growth of this new 'experience economy' and the concept brought to life. Kelly and Littman (2008) apply the concept beautifully within 'design thinking', describing how consumers have replaced the trend for gathering up 'items' and now fill 'boxes' with memories, stories and experiences.

Poulsson and Kale (2004) discuss the relevance of the experience economy to the adventure sport industry and highlight the; 'growing trend of people enthralled with seeking out extraordinary experiences and willing to pay generously for them' (Polusson and Kale, 2004, p. 269). They also note that; 'consumers are scouring the globe in search of experiences that are relevant and engaging' (Polusson and Kale, 2004, p. 269).

The 'experience economy' is one of the contributors to the exceptional growth rate of the adventure sport industry, and the desire to become an adventure sport participant shows no signs of waning. Breivik (2010) makes sense of this and discusses the understanding that the adventure sport industry may offer consumers things they find difficult to achieve in other sports, activities, or industries. Breivik explains;

'adventure sports point to key ideas and developments in modern and post-modern society such as individualism, technology, self-realization and transcendence' (2010, p. 261).

He predicts that more females are likely to become engaged with this movement, however, states that these women;

'may become trendsetters in some of these activities' (2010, p. 261).

Much has been written that has allowed us to develop an understanding of the 'experience economy', and its influence on the growth of the adventure sport industry; however, it is unclear why female participant figures have not grown in line with this trend. 


\section{Gender Differences in Adventure Sport}

Members of any group, be it gender, ethnic, or minority group, can experience barriers when accessing adventure sport activities (Anderson \& Noble, 2001). It is fair to say that some barriers are generally perceived to be exclusively experienced by one gender or the other. However, it could also be argued that barriers can be effectively the same for both genders, and that it is gender traits, and the way one gender deals with the barrier in comparison to the other gender, that can be the real issue. Although the focus of this paper is to identify and highlight barriers experienced by female adventure sport participants, the researcher realises that there is potential for the barriers that are discussed within this paper to also be experienced by males, and therefore recognises potential for further research to specifically explore variations between how males and females experience and deal with any barriers that may arise during their participatory journey and/or experience(s). Regardless of this, it is clear that even though females express an enthusiasm for becoming established members of the adventure sport community, they continue to experience barriers to participation, and, as such, remain underrepresented in comparison to their male counterparts (Coalter \& Dowers, 2006).

Female underrepresentation within the adventure sport industry is a global issue. Stoddart (2011) highlights the physical impact and requirements of many adventure sports, making it clear that it is highly unlikely there will ever be an equal split of male-female participants. Research does indicate that more females would like to become regular participants, even though they are aware that they may never have the capacity to operate on the same par as their male counterparts in the majority of activities, for example, where body strength is required. However, Laurendeau and Sharara (2008) explore the notion that there is nothing to suggest females cannot participate to the full extent of their own strength and ability, and in fact they may even perform better than their male counterparts in those activities where participants have a greater advantage if they are smaller, lighter, or where more intricate technical skills are required, for example, skydiving and ski jumping.

\section{Exploring Lived Experiences}

According to Heidegger (1962) 'humans as beings are primarily concerned about their existence and seek to understand it', and it is this understanding that Pernecky and Jamal (2010) believe:

'...occurs through our culturally and historically mediated interpretations and relationships with objects and things, and through the social meanings contained in language'.

To gain this deep understanding of the lived experience Smith, Flowers and Larkin (2009) suggest it imperative for the researcher to engage in a rigorous and iterative process of explication (Brymer \& Schweitzer, 2013). It is this process that allows for the deep understanding of the lived experienced that the researcher may interpret and make sense of. Taking a hermeneutic approach has, in this study, allowed the researcher to understand the meanings behind the experiences, gained during the ethnographic and auto-ethnographic phases of the study, giving a deeper understanding of not just the experience itself, but also the traditions, heritage, history and social implications that come with being an adventure sport participant. 
Pernecky and Jamal (2010, p. 1055) discuss the potential of hermeneutical phenomenology in exploring experiential issues related to being-in-the-world (Heidegger, 1996), however note the use of such be largely unexplored within the tourism industry and suggest there be value in applying this method in order to study, better understand, and explore lived experiences.

Taking a qualitative approach is not normally aligned with traditional research methodologies in this field and Pernecky and Jamal (2010) suggest that publications generally avoid phenomenological discussion (Ritchie, Burns and Palmer, 2005; Veal, 1992) and approaches (Jennings, 2001). One possible reason for this is the lack of clear methodical guidance on its use (Obenour, 2004), especially within research focusing on the 'experience economy'. A second reason, offered by Pernecky and Jamal (2010), is that;

'...phenomenological research is highly complex; it is time-consuming, requiring active researcher's involvement, attentiveness and knowledge of the philosophical underpinning of the particular approach'.

However, Jennings (2001) notes there has been an increase in, and emphasis on the emerging use of, qualitative approaches. Jennings specifically refers to tourism studies, a field which has traditionally favored the use of scientific and quantitative methods. However, his findings are transferable and could also be applied within studies focusing on the 'experience economy'. As such, implementing this type of approach within the study was considered to be potentially risky, however, it was felt that exploring the feasibility of such approaches could be useful in establishing a framework for future studies of a similar nature.

\section{Methods}

\section{Approach}

A qualitative data collection approach was designed and implemented.. The study was not designed to establish the processes implemented by these participants, which effectively allowed them to become established adventure sport participants, but rather took a phenomenological perspective - reflecting on their lived experiences. The methodology looked to explore the meaning(s) behind their actions and the decisions that influenced and formed individual journeys. It was also hoped that by taking a qualitative approach a framework of methodologies would emerge which could be implemented within future studies, and one that may have potential to be transferable for use within other disciplines..

The study took place over the course of 18 months, in various locations within Scotland including the Cairngorms National Park, the Fort William and Glen Coe areas, and the Highland Perthshire area. Ethical consent was obtained from the University of Abertay Dundee Ethical Committee. Informed consent was obtained from all participants.

Three methodologies were implemented during the study:

i. Auto-ethnography: making use of the researchers own experiences as an adventure sport participant;

ii. Ethnography: based on observatory and participatory activity conducted by the researcher; and, 
iii. Interviews: conducted with female adventure sport participants.

\section{Recruitment}

Recruitment for the auto-ethnographic and ethnographic elements of the study were conducted on the basis that the researcher was in a position to undertake field study style activities as and when the opportunity for such arose, in that opportunities were actively sought out, but also taken up on the event that the offer of such was presented to them. Additional participants were not specifically recruited to contribute data to this phase of the study, however, others (participants) encountered during the course of data collection were advised of the nature of the study and informed that they may contribute data, but that the data collected would be analyzed in such a manner that reflect the researchers own experiences and would not necessarily be attributable to a specific participant or group of participants. In terms of numbers of participants, the total number was not recorded, however 32 individual participants and six groups of participants contributed significantly to the study. All confirmed they understood the nature of the study and how the data was intended to be used.

From a gender perspective; specific criteria were not implemented, and participants were not excluded based on gender. This allowed data to be collected and theories to be formulated that provided a basis for comparison and ensured that perspectives were gathered from both male and female participants. Similarly, the study did not set out to explore perspectives of just one skill level group, but rather looked to consider the perspectives of participants from all levels of skill including novice, intermediate, advanced and professional groups. Data collected in this respect fed into the decisions used to establish the most appropriate approach required for the interview phase of data collection.

For the interviews, an observation process was undertaken for a period of nine months whereby potential participants were monitored using social media and by direct communication (in writing and face-to-face). During this period a number of participatory activities were conducted with potential interview participants. This was to assess their suitability for the study. This pre-interview process provided the opportunity to form a relationship with the potential participants, as well as forming an understanding of the motivations of female adventure sport participants. During this period of observation, it was possible to begin formulating the most appropriate set of questions to be used during the interviews proper. Rather than canvassing for interview participants, this approach allowed those participants with the potential to provide the richest and most relevant data (to the study) to emerge. During the pre-interview process potential interview participants were contacted directly by the researcher, however others also came forward to offer their contribution. Following the observation process the decision was taken to interview two of the female participants.

\section{Data Collection}

\section{Auto-ethnography and ethnography}

Data was collected in the first instance using ethnographic and auto-ethnographic methods, making use of the researchers own lived experiences as an adventure sport participant. The researcher spent periods of time conducting field-style data collection activities including 
participating in adventure sport activities alongside other participants, and under the guidance and/or instruction of professional level participants. Activities participated in included skiing, ski touring, cross-country (Nordic) skiing, hill walking, off-road trail and hill running, rock climbing, Scottish winter climbing, and Alpine via ferrata. Figure 1 below gives an outline of some of the activities participated in as part of the data collection conducted in Scotland. The researcher was not necessarily competent in each of the activities before embarking on the study and was therefore, as part of the study, required to learn new skills and techniques following the same process that would be undertaken by a novice adventure sport participant. Taking this approach allowed for 360-degree perspective to be obtained, in terms of being a participant of adventure sport activities, and also permitted exposure to those participants from a range of skill level groups.

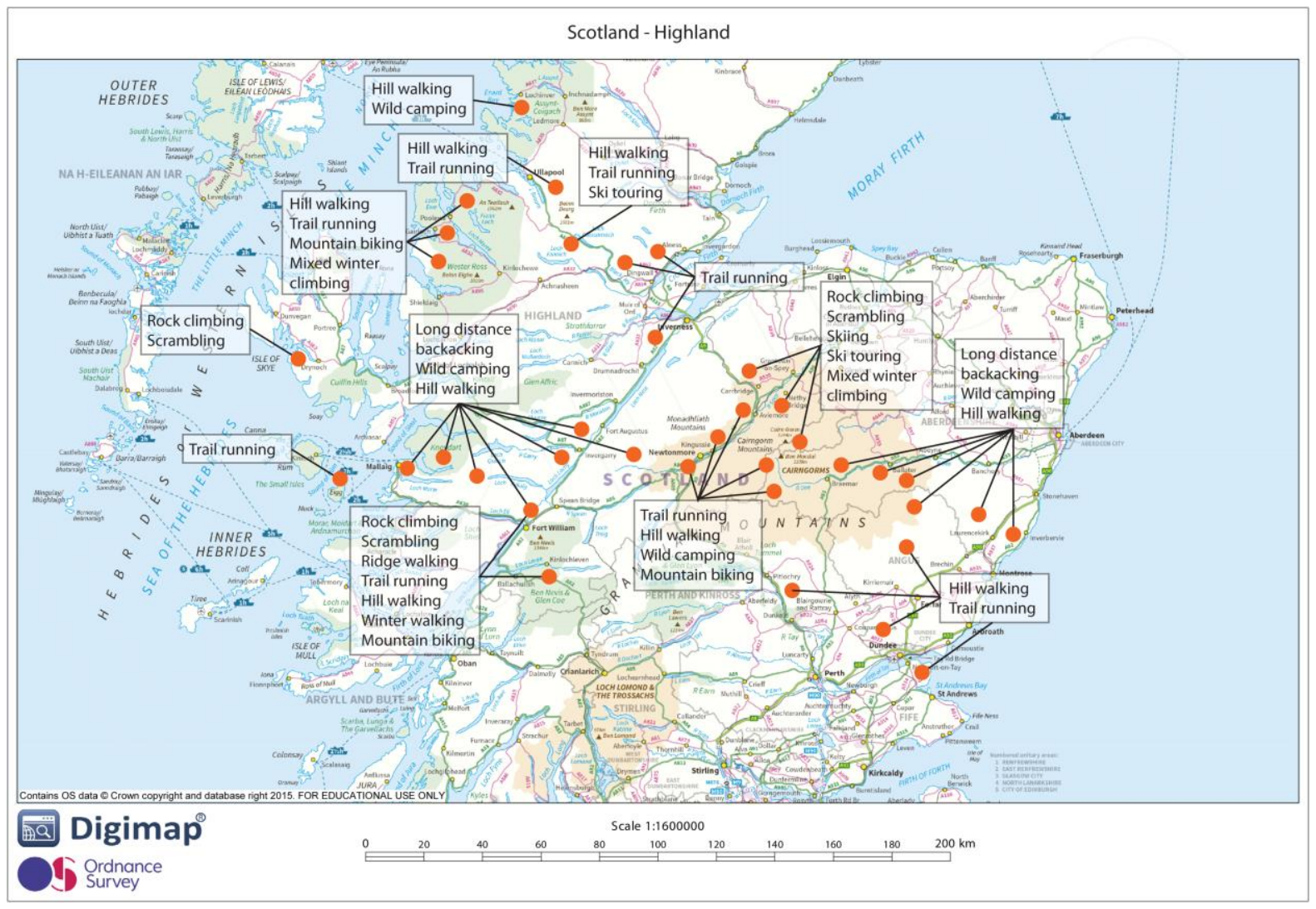

Figure 1: Map of adventure sport activities participated (Scotland).

Source: @ Crown Copyright and Database Right 2017. Ordnance Survey (Digimap Licence).

Data was recorded using researcher notes (some of which were transcribed verbatim, others transcribed in note style, some extracted for analysis directly from the original notes), photographs, and an online blog (WordPress). Social media (Facebook, Twitter and Instagram) tools were also used as a form of generating dialogue(s) with other adventure sport participants, and also used as a way of identifying locations, activities, groups etc. which it may have been open to being part of the study, in that the researcher was permitted to join on either an observatory or participatory basis. 
In the first instance, data was collected during a twelve-month period spent in Scotland. The researcher lived and participated as an adventure sport participant, including spending time on the road traveling with other adventure sport participants and sharing accommodation with the same. This period of immersion allowed data to be collected in a number of environments and situations. There was also opportunity to collect comparative data which could be viewed as a complete lived experience. This provided insights into how participants behaved while participating in adventure sport activities, how they behaved when planning to participate, and how they behaved when not participating. Comparison was able to be made about how participants behaved when in the company of other participants, differences were observed based on the general skill level of the group they were participating with and their role within that group. Different behaviors were observed when participants were in the company of those who did not participate in any adventure sport activities.

\section{Interviews}

Interviews were conducted as part of the data collection process in order to elaborate on, and validate the findings which had emerged from the ethnographic and auto-ethnographic phases of data collection. The process used to select interview participants was rigorous and a number of factors, including experience, skill level and initial motivations for participating in adventure sport activities were explored in depth with each potential interview participant as part of the selection process. Following the selection phase, two females were contacted and asked if they would be willing to contribute to the study.

It could be argued that a sample size of two interview participants is not sufficient for a study of this nature, however, the selection process assisted in informing the study as a whole, also the reasoning behind conducting interviews as part of the study was considered necessary in order to validate findings which emerged following the ethnographic and autoethnographic activities. It was appreciated that it may be necessary to canvas for a further sample of interview participants, however, following the interviews which took place over a residential-style activity weekend (two days), confidence was applied to the data and was considered sufficient in informing the study. Furthermore, one objective of the study was to conduct the study on using only qualitative methods, and the need to include modal and/or statistic findings (which is what would have begun to emerge had a larger number of interviews been conducted) typical of a mixed methods and/or quantitative study was considered unnecessary.

Female participants were specifically sourced because the initial line of inquiry was focused on exploring barriers that females experience when accessing adventure sport activities. Male participants were not excluded from the study as a whole since they were part of the ethnographic activities, however, the decision was taken not to include male participants during the interview process, since their opinions and views had been recorded during the ethnographic phase of the study. All females identified as being potentially suitable for participation in the study were in their early 30's and of white British descent. All were based in the UK and in full-time employment.

The female adventure sport participants selected for interview as part of the study were chosen on the basis that they had a sufficient amount of adventure sport experience and met the following criteria:

1. participated on a regular basis for at least three years, 
2. had sampled a range of adventure sport activities,

3. participated in adventure sport activities for their main holiday,

4. participated in adventure sport activities for short and weekend breaks,

5. participated in adventure sport in Scotland, the UK and Internationally, and;

6. were recognized as having made a significant contribution to, and received recognition for this contribution, in at least one adventure sport activity.

A weekend break (two days) was organized and set-up to take the form of an adventure sport activity break. The nature of the weekend allowed for much open dialogue and exchange of ideas, information and experiences. Both participants were happy for communication and data gathered outside of the recorded interview to be used as part of the study. This holistic approach allowed the participants to relax and enjoy the research process. It is believed that allowing the participants to communicate their narratives in the very environment with which they feel most attachment and comfort generated rich data relative to the study and allowed unexpected dimensions to emerge.

Interviews were conducted on the afternoon of day one following a morning of participating in an adventure sport activity (trail running). Interviews were structured and explored reasons for participation and barriers experienced when assessing adventure sport activities. In addition to the pre-defined interview questions, the interview subjects were prompted to elaborate on answers, or answer impulse questions that were prompted by given responses. The interview participants were not questioned in any manner that implied they had indeed faced any barriers when accessing adventure sport activities. The initial approach to request their participation did not imply they had faced any problems and/or barriers.

Interviews were recorded using a digital recording device and later transcribed verbatim. Ethnographic researcher notes were recorded following both days during the weekend, and reflexive notes were made a number of days following the interviews. Photographs were also taken during the weekend. Ethnographic notes were recorded after the interviews took place, to record observations recalled from the interview process including thoughts of potentially unspoken communication. Findings recorded outside of the interview were also documented, with the permission of the interview participants.

\section{Analysis}

Audio transcripts were thematically analyzed alongside researcher notes, memos, photographs, blog entries and written communications such as emails and social media interactions. Data was reduced in the first instance into themes to ensure no loss of descriptive data occurred. The analysis process was conducted using a grounded theory approach, but also drew influence from a hermeneutic phenomenological approach whereby experiences were reflected upon, descriptions were illuminated and probed, and clarification was sought, thus allowing the findings to be based on more than observation (Flood, 2010; Munhall and Oiler 1993; Kvale, 1996; Jasper, 1994). Collected data was analyzed using a six phase process:

i. Immersion: transcripts were read and re-read to identify descriptive codes; 
ii. Initial coding: descriptive codes were manually extracted and systematically transferred to a data sheet, and then analyzed for central codes;

iii. Theme identification: central codes were analyzed for thematic codes, and allocated to the appropriate descriptive code (some overlapping occurred at this stage);

iv. Defining: thematic codes were elaborated upon, and associated with the appropriate central code;

v. Reviewing: all data was reviewed - themes were noted, stages i., ii., iii. and iv. were repeated to ensure no loss of data relative to the study, and to eliminate any duplicated data (codes).

vi. Refining: thematic codes were refined and defined.

\section{Results and Discussion}

The aim of the study was to explore, using qualitative methods, barriers which may be experienced by female adventure sport participants when attempting to access adventure sport activities in Scotland on a regular basis. There is a good deal of information in existing literature that leads us to the understanding that the number of people accessing adventure sport activities has increased significantly, and this can be associated, in part, by the emergence of the 'experience economy' (Pine and Gilmour, 1999). There is also information about gender division of participants, and it has been noted that the growth rate for female participants is not on a par with that of male participant figures. As such, overall growth can be attributed to the experience economy, however, we do not have a clear understanding why the figures for male participants continue to outweigh the figures for female participants.

Literature does indicate a desire for females to become established adventure sport participants, and there is a widely documented understanding that females may even have the potential to outperform males in certain adventure sports (Laurendeau \& Sharara, 2008). Breivik (2010) predicts female participant figures will eventually match that of male participant figures, however, there is little documented about how this might emerge, nor the reasons, or barriers, that may have prevented it emerging thus far.

Essentially, there are certain factors that will always cause barriers for females accessing certain adventure sports, for example; strength, risk-perception, family commitments. For some females, the ability or opportunity to overcome these long-established gender-specific barriers might never emerge. Barriers to achieving any objectives are, of course, much more complex than those that present themselves as 'typical' or 'obvious'. Using this study to explore the lived experiences of established adventure sport participants has allowed an insight into discovering what the 'hidden' barriers to participation might be, and has allowed the researcher to find meaning in these experiences, and uncover unspoken barriers that may indeed impact a female's ability to becoming an established adventure sport participant.

Interview participants were questioned about their journey as adventure sport participants, considering their starting point and thinking about the decisions they had made, and how they had made those decisions. They were also asked about their current connection with the adventure sport industry and probed about plans for future participation. It was never posed to the interview participants that they may have experienced barriers, nor did any of the questions directed to them imply they had experienced barriers. When it organically emerged 
as part of the conversation that they may have faced a barrier to participation, they were prompted to elaborate on this, and occasionally posed suggestions that may change or enhance their experience were they to repeat it.

During the ethnographic and auto-ethnographic phases of the study the researcher spent time with both male and female participants - taking part in adventure sport activities alongside them; with them in the lead role, with the researcher taking the lead role and in social situations. The study did not just focus on participating alongside these participants on a day-to-day basis or on a multi-day basis, but included periods of residing in the same accommodation and traveling (to different/alternative adventure sport locations) for long periods of time with these participants. Doing this allowed relationships to grown and develop, and to gain an insight into the more in-depth facets of being an adventure sport participant including the community, mindset and difficulties experienced out with actual participation. Taking an auto-ethnographic approach effectively assisted in the development of a complete understanding of the lifestyle and lived experiences of an adventure sport participant without disrupting the equilibrium. Any adventure sport participants with whom time was spent was fully aware of the intentions and motivations of the researcher.

Following analysis five key themes emerged that could be considered as barriers to participation. Each factor emerged in different contexts and within different narratives recounted in various ways and applied to different experiences.

1. Cost: High cost of skills courses, kit and equipment - this was tied in with the amount of activity-specific kit required to participate.

2. Information: Lack of accurate, appropriate, and genuine information referencing both print and online information sources.

3. Support: Lack of support and understanding from family and friends who were not adventure sport participants themselves.

4. Perception: Feeling that media communication portrays adventure sport as extreme and risky.

5. Community: Feeling intimidated by professionals and established members of the adventure sport community.

\section{Themes}

\section{Theme One: Cost}

The first theme relates to costs associated with adventure sport participation, and could of course be considered an obvious factor. Indeed, it is fair to say that any trend, concept, service or product for which there is high demand often has high costs associated with it. Therefore, it doesn't seem like a particularly revolutionary observation that cost be a barrier to participation. However, when applied to the experiences of adventure sport participants many of whom were in their 30's, and with existing financial commitments unassociated with adventure sport participation (such as mortgage payments, motor running costs, childcare), and then linked with other themes (such as Theme 3: Support) which emerged during the analysis, one begins to see connections and realize there is perhaps more to this particular barrier than visible on the surface; Interview Participant One (female, sea kayaker, trail runner and mountain biker, 32) explains;

'...cost is a key factor against participation, at first cobbling stuff [clothing and equipment etc.] together is fine, but kit and participation costs mount up...image is 
important like having the right stuff, but it all mounts up and then you have other commitments too...'.

\section{Theme Two: Information}

The second theme that emerged was the need for information, specifically information that could be relied upon, and was successful in meeting the specific needs of the individual, while being genuine and accurate. The need to be able to access information that is based on more than simply; "matter of opinion" (Interview Participant One) was discussed at length. Interview Participant Two (female, skier, climber and adventure sport writer, 31) goes on to say:

'...looking for information on the internet is like looking for a needle in a haystack. How can you be sure you're looking at the right thing? Information is just not easy to access, the internet has too many conflicting opinions.'

Guidebooks were considered to be the most reliable source of information, however concern was discussed in respect of how current the information was, since conditions, routes and local information may have changed since the time of printing. Additionally, industry specific magazines were thought to be a good way of obtaining up-to-date information, but there was the worry of how much influence advertisers had over the final content printed in the magazines.

\section{Theme Three: Support}

Almost all of the adventure sport participants encountered throughout the course of the study discussed support as being one of the key factors required in order to be able to become, and eventually be, an adventure sport participant. Support was not always discussed as being something that was readily offered. Reasons for this varied and it may have been that family and friends simply wanted to spend more time with the participant but were not interested in doing so within an adventure sport setting or by participating in an activity alongside the participant, or perhaps they did not understand the level of commitment required in order for the adventure sport participant to meet their goals.

This has potential to cause impact to the female adventure sport participant; if she does not have the necessary support and understanding from family and friends, there is a possibility that they may be unintentionally pressured into using financial resources to participate in activities outside of adventure sport activities, or to turn down an opportunity to participate (weekends and time away from the home were specifically mentioned in this respect). There was nothing to suggest, that females have any issues participating in activities with family and friends, however, in doing so; are they putting themselves at a disadvantage, and indeed experiencing a barrier by doing so?

It is most likely that family and friends are completely unaware of this barrier and there was no indication, spoken or unspoken, that there be an intentional motive to cause a barrier to participation, however, it was reported that family and friends would regularly communicate feelings of confusion as to why one would choose to participate in adventure sport activities, displaying emotions described as fear, anxiety and worry. Essentially, this is a theme with much scope for further research. 


\section{Theme Four: Perception}

This theme relates closely to media communication, or rather the regularly manipulated media communication (Holland-Smith and Olivier, 2013) that often portrays the adventure sport industry as risky, trilling and adrenaline-fueled. Brymer (2010) argues that the real ethos of the adventure sport industry is quite the opposite, and that professional participants are beginning to communicate a deep dislike of the thrill-seeking label placed on them by media communications. Interview participants discussed this as an important factor and one that regularly influenced their decision to participate, at what level to participate, and in which environment they would be capable of participating in. It was clear they underestimated their own level of ability, a trait common in females, but it was very apparent they felt they were not as accomplished and skillful as they perhaps genuinely were.

During the study, it became very clear there was a distinct different between genders in respect of how approach participating in adventure sport activities and being an adventure sport participant, monitoring of online and social media communications (such as forums, chat rooms, Facebook, Twitter, Instagram) demonstrated a real feeling of adrenaline, risk, and pushing the boundaries - this was a trait noted to be more common in male participants, females tended toward sharing group experiences and more emotive narratives. When this was explored during the interviews, both participants agreed that; 'imagery to aspire to is great' (Interview Participant Two), but there was greater need for imagery that communicates an obtainable objective/goal. Furthermore, brand image was discussed as a key driver contributing to the increase in media portrayal of adventure sport and participants thought that stores, the people, magazines and websites were for the most part too full on/hardcore, and aimed more at professional level participants, with not enough available for the average and/or novice level participant.

\section{Theme Five: Community}

From the outset of the study, the need to be part of the adventure sport community was very apparent. In order to arrange and conduct almost all of the ethnographic and autoethnographic data collection activities planned as part of the study, it was essential to make effort, and to sustain such effort, to build relationships with members of the adventure sport community. Doing so allowed data to be collected from sources that could be trusted and relied upon to provide honest data sets. Interview participants confirmed this finding, Interview Participant Two said:

'These sorts of sports really rely on others in order to participate, it's all about building relationships and trust.'

She then went on to discuss her experience in respect of the adventure sport community:

'I don't feel like a member of the community, it can be intimidating to approach someone when you feel like you don't know something...the different communities [e.g. mountain bikers, climbers, etc.] don't really merge...'

One might assume, that established female adventure sport participants, participating on a regular basis, would feel themselves to be members of the adventure sport community, however, many indicated a feeling of intimidation when approaching an established adventure sport participant - most likely male. And explicitly stated that they did not feel a part of the adventure sport community, believing themselves to be both inadequately 
qualified and under-experienced, and not having completed the appropriate 'service time' to prove themselves worthy of membership.

It did become clear during the auto-ethnographic study that the adventure sport community has a rich heritage and tradition that has deep-rooted, but unwritten guidelines as to how one might be recognized as a member of the adventure sport community. It seems uncertain how one can assess themselves as being a part of the community; one just 'seems to know'. How the transition happens and how long it can take is unclear. The level that one needs to participate at is also unclear. However, one thing is clear, the adventure sport industry is undergoing a phase of change, perhaps even evolution, and the impact of such felt by the adventure sport community could be a point of interest in the future.

\section{Conclusion and Future Study}

Taking a theoretical perspective toward attempting to better understand female underrepresentation within the adventure sport industry, the study utilised ethnography, autoethnography, interviews and open narrative to collect data, this data was thematically coded and analysed by taking a grounded theory approach and drawing on hermeneutic phenomenological theories. The interview participants discussed their journey from first point of contact with the adventure sport industry through to current involvement. Using this methodology and approach, allowed the researcher to take a 'lived experience perspective'.

The study discusses barriers that some females may encounter when accessing adventure sport activities in Scotland, and proposes how those barriers may be interwoven and so intrinsically linked that they are indeed not always interpreted as barriers. However, beneath the surface, they may be the very factors that are preventing some females from accessing adventure sport on a regular enough basis to allow them to meet the necessary criteria to become established members of the adventure sport community, and thus encourage an increase in female participation statistics.

This understanding presents complex issues, and a number of conclusions have been drawn from the findings:

1. Females encounter unspoken barriers that prevent them from participating in adventure sport in rural Scotland.

2. The barriers are potentially hindering the progress of these females - preventing them from becoming established members of the adventure sport community, and thus, preventing them from benefitting from what that community can offer them.

3. These barriers are not superficial and may require perceptions to be changed in order to break down the barriers.

Further research is required to develop these findings and to present an appropriate and comprehensive solution. The adventure sport industry in Scotland is clearly changing. Exactly how the adventure sport industry will look in the future is unclear, but it could be proposed that to begin addressing female underrepresentation within this industry those who create media communication could better focus their efforts on producing less 'extreme' material and portraying a more genuine and realistic image of what the adventure sport industry really is, and those who make up the community. 
Implementing a solution could have the following impacts:

1. Create a truer image of the adventure sport industry for those who are not participants - therefore easing the 'please don't do that' pressures from family and friends towards female adventure sport participants.

2. Established adventure sport participants will be portrayed in the honest light they yearn for - not as 'out of control' and 'adrenaline junkies'.

3. Portraying the 'real' image of the adventure sport industry could begin in breaking down the barriers between these females and established members of the adventure sport community. 


\section{REFERENCES}

Anderson, Andy, and Kirsty Noble. An analysis of regional variations in Sports Participation in Scotland. Edinburgh: SportScotland (85), 2001.

Breivik, Gunnar. "Personality, sensation seeking and risk taking among Everest climbers." International Journal of Sport Psychology 27:3 (1996): 308-320

Breivik, Gunnar. "Trends in adventure sport in a post-modern society." Sport in Society 13:2 (2010): 260-273.

Brymer, Eric, and Robert Schweitzer. "The search for freedom in extreme sports: A phenomenological exploration." Psychology of Sport and Exercise 14:6 (2013): 865873.

Brymer, Eric. "Risk taking in extreme sports: A phenomenological perspective." Annals of Leisure Research 13:1 (2010): 218-238.

Celsi, Richard, L., Rose Randall, and Thomas Leigh. "An exploration of high-risk leisure consumption through skydiving." Journal of Consumer Research 20:1 (1993): 1-23.

Coalter, Fred, and Steve Dowers. An analysis of regional variations in sports participation in Scotland. Edinburgh: SportScotland (105), 2006.

Flood, Anne. "Understanding phenomenology.” Nurse Researcher 17:2 (2010): 7-15.

Heidegger, Martin. Being and Time. New York: HarperOne, 1962.

Holland-Smith, David, and Steve Oliver. "'You don't understand us!': an inside perspective on adventure climbing." Sport in Society 16:9 (2013): 1-14.

Jasper, Melanie, A. "Issues in phenomenology for researchers of nursing." Journal of Advanced Nursing 19:2 (1994): 309-314.

Jennings, Gayle. Tourism Research. Milton: John Wiley \& Sons Australia Limited, 2001.

Kelley Tom, and Jonathan Littman. The ten faces of innovation: IEDO's strategies for beating the devil's advocate and driving creativity throughout your organization. London: Profile Press, 2008.

Kerr, John, H., and Susan Houge Mackenzie. "Multiple motives for participating in adventure sports." Psychology of Sport and Exercise 13:5 (2012): 649-657.

Kvale, S., 1996, InterViews: An Introduction to Qualitative Research Interviewing, Sage Publications, Thousand Oaks, CA.

Laurendeau, Jason, and Nancy Sharara. "Women could be every bit as good as guys: Reproductive and resistant agency in two 'action' sports." Journal of Sport and Social Issues 32:1 (2008): 24-47.

Obenour, William, L. "Understanding the meaning of the 'journey' to budget travellers." International Journal of Tourism Research 6:1 (2004): 1-15.

Pain, Matt, T., G., and Matthew A. Pain. "Essay: Risk talking in sport.” The Lancet 366:1 (2005): S33-S34. 
Pernecky, Tomas and Tazmin Jamal. "(Hermeneutic) phenomenology in tourism studies." Annals of Tourism Research 37:4 (2010): 1055-1075.

Pine, B. Joseph, and James H. Gilmour. The experience economy: Work is theatre \& every business a stage. Boston, Mass: Harvard Business School, 1999.

Poulsson, Susanne, H., G., and Sudhir H. Kale. "The experience economy and commercial experiences." The Marketing Review 4:3 (2004): 267-277.

Puchan, Heike. "Living 'extreme': Adventure sports, media and commercialisation.” Journal of Communication Management 9:2 (2004): 171-178.

Ritchie, Brent, W., Peter Burns, and Catherine Palmer. Tourism research methods: Integrating theory with practice. Wallingford: CABI Publishing, 2005.

Schmitt, Bernard, H. Experiential Marketing. New York: The Free Press, 1999.

Slanger, Elissa and Kjell Erik Rudestam. "Motivation and disinhibition in high risk sports: Sensation seeking and self-efficacy" Journal of Research in Personality 31:3 (1997): 355-374.

Smith, Jonathan, A., Paul Flowers, and Michael Larkin. Interpretive Phenomenological Analysis: Theory, Method and Research. London: Sage, 2009.

Smith, Laura, Mary Lynn Hamilton, and Kristen Worthington. "Fitting the methodology with the research: An exploration of narrative, self-study and auto-ethnography." Studying Teacher Education 4:1 (2008): 17-28.

Stoddart, Mark, C., J. "Constructing masculinised sportscapes: Skiing, gender and nature in British Columbia, Canada." International Review for the Sociology of Sport 46:1 (2011): 108-124.

Veal, Anthony J. Research methods for leisure and tourism. Essex: Longman Group UK Limited, 1992. 